\title{
Site-Specific Carbon-Carbon Bond Fission in Photoexcited Propyl Radicals Leads to Isomer-Selective Carbene and Radical Products
}

\section{Supporting Information}

Journal of Physical Chemistry Letters

Sagnik Datta ${ }^{1}$ and H. Floyd Davis ${ }^{1 *}$

${ }^{1}$ Department of Chemistry and Chemical Biology, Cornell University, Ithaca NY 14853-1301.

*Correspondence to: hfd1@cornell.edu

\section{Table of Contents:}

Materials and Methods $\quad$ S2

Supplementary Text $\quad$ S3

Supplementary Figures (S1 to S7) S8

References $\quad$ S15 


\section{Materials and Methods}

\section{i. Experimental Details}

The experiments were carried out using a rotatable source crossed molecular beams apparatus with fixed mass spectrometer detector. ${ }^{1}$ The neutral products were ionized by photoionization at $9.9 \mathrm{eV}$ using a high intensity pulsed vacuum ultraviolet laser. ${ }^{2}$ The positive ions entered a quadrupole mass filter and were then counted. The arrival time distribution for a given $\mathrm{m} / \mathrm{e}$ was recorded by scanning the delay of the ionization laser relative to the photolysis laser pulse using a digital delay generator.

The radicals were produced by flash pyrolysis ${ }^{3}$ of 1- or 2- azopropane, synthesized according to the method of Renaud and Lietch, involving three steps for each isomer. ${ }^{4}$ Careful purification by fractional distillation was carried out after each step. The NMR spectra of the final synthesized products were recorded using a Varian Innova $500 \mathrm{MHz}$ NMR spectrometer. The NMR spectrum of 2-azopropane (figure $\mathrm{S} 1$ ), in $\mathrm{CDCl}_{3}$, using tetramethylsilane as the internal standard, showed peaks at $\delta$ (in ppm) $=1.25$ (doublet), $\mathrm{J}=6.6 \mathrm{~Hz}$; and 3.55 (heptet), $\mathrm{J}=6.5 \mathrm{~Hz}$. Similarly, in the case of 1-azopropane (figure S2), the NMR spectrum consisted of peaks at $\delta$ (in ppm) $=0.98$ (triplet), $\mathrm{J}=7.4 \mathrm{~Hz} ; 1.84$ (hextet), $\mathrm{J}=7.3 \mathrm{~Hz}$; and 3.75 (triplet), $\mathrm{J}=7.1 \mathrm{~Hz}$. On the basis of the integrated peak heights in the NMR spectra, the purities of the azo compounds were greater than $98 \%$.

A dilute $(\sim 2 \%)$ mixture of the azoalkane was formed by bubbling He (ultrahigh purity) at a total pressure of 8 PSIG through a liquid sample held in a stirred refrigerated bath, maintained at $0^{\circ} \mathrm{C}$ for 2-azopropane and $18^{\circ} \mathrm{C}$ for the less-volatile 1-azopropane, respectively. It was found that the highest radical intensities were obtained using a very short ( $\sim 6 \mathrm{~mm}$ long) pyrolysis tube, maintained at a relatively low $(\sim 800 \mathrm{~K})$ pyrolysis temperature. This is consistent with the very weak R-N bond strength $(\sim 210 \mathrm{~kJ} / \mathrm{mol})$ in the parent azo compound, $\mathrm{R}-\mathrm{N}=\mathrm{N}-\mathrm{R}$, which is known to dissociate thermally to produce $2 \mathrm{R}+\mathrm{N}_{2} .{ }^{5}$ Note that $\mathrm{RN}_{2}$ produced after scission of the first $\mathrm{R}$ $\mathrm{N}$ bond in the azoalkane is not expected to be present since it is highly unstable, undergoing rapid dissociation to $\mathrm{R}+\mathrm{N}_{2}{ }^{5}$ Due to the weak $\mathrm{C}-\mathrm{H}$ bond ${ }^{6}$ in propyl radicals, excessive pyrolysis temperatures or longer pyrolysis residence times led to significantly decreased radical intensities 
and increased levels of $\mathrm{C}_{3} \mathrm{H}_{6}$ impurities. Note that the parent azo compounds and the $\mathrm{C}_{3} \mathrm{H}_{6}$ byproducts do not absorb significantly at $248 \mathrm{~nm}$, whereas propyl radicals have very large absorption cross sections at this wavelength.

During the course of this work, a number of potential radical sources were tested, including pyrolysis of nitrites and photolysis of iodoalkanes and nitroalkanes. However, the radical concentrations from the azo compounds under optimum conditions, measured by direct mass spectrometric sampling of the beams using $20 \mathrm{eV}$ electron impact ionization or photoionization at 8.8 or $9.9 \mathrm{eV}$, were much higher than from optimized conditions using the alternative methods, in some cases by an order of magnitude. We found that pyrolysis of nitrites led to very large levels of impurities.

The pyrolytic radical beam was collimated by passage through two skimmers and crossed by the $248 \mathrm{~nm}$ output of a Lambda Physik Compex 110 pulsed excimer laser attenuated using fine mesh screens $(20 \mathrm{~mJ} / \mathrm{pulse}, 20 \mathrm{~ns}, 30 \mathrm{~Hz}, 3 \times 5 \mathrm{~mm})$. A small fraction of the photodissociation products scattered out of the beam through a set of defining slits to a liquid nitrogen cooled triply differentially pumped detector.

\section{Supplementary Text}

\section{i. Secondary C-C Bond Fission Channel in the Photodissociation of 1-Propyl Radicals}

For 1-propyl radical photodissociation, we observed weak signals at $\mathrm{m} / \mathrm{e}=15$, corresponding to a secondary $\mathrm{C}-\mathrm{C}$ bond fission channel producing $\mathrm{CH}_{3}$ and $\mathrm{C}_{2} \mathrm{H}_{4} / \mathrm{CH}_{3} \mathrm{CH}$. In figure $\mathrm{S} 3$, the TOF spectrum for the $\mathrm{m} / \mathrm{e}=15$ products from photodissociation of 1-propyl radicals are shown. The solid red lines are the optimized TOF spectra, calculated using the $\mathrm{P}(\mathrm{E})$ shown in the lower portion of the figure.

Within the available signal-to-noise ratio, the $\mathrm{P}(\mathrm{E})$ for this channel is very similar to that for the major $\mathrm{C}-\mathrm{C}$ bond fission channel from photodissociation of 2-propyl radicals. The possible origins of the $\mathrm{m} / \mathrm{e}=15$ products are discussed in the main manuscript. 


\section{ii. C-H Bond Fission in 2-Propyl Radical at 248 nm}

During the course of this work, we also observed C-H bond fission in the $248 \mathrm{~nm}$ photodissociation of 2-propyl radicals. As illustrated in figure S4, we recorded experimental TOFs at $\mathrm{m} / \mathrm{e}=42$, corresponding to the nascent $\mathrm{C}_{3} \mathrm{H}_{6}$ (propene) $+\mathrm{H}$. products. The solid blue lines are the optimized TOF spectra, calculated using the $\mathrm{P}(\mathrm{E})$ shown in the lower portion of the figure. Due to the constraints of momentum conservation, the "heavy" propene products are constrained to small laboratory angles relative to the molecular beam. Our apparatus in its present configuration is not well suited to $\mathrm{H}$ atom detection $(\mathrm{m} / \mathrm{e}=1)$, due to large background signals. In addition, due to the presence of free $\mathrm{C}_{3} \mathrm{H}_{6}$ in the beam, and photoinduced fragmentation of $\mathrm{C}_{3} \mathrm{H}_{7}$, the background signals at $\mathrm{m} / \mathrm{e}=42$ rise sharply at decreasing beam-detector angles. For this reason, the smallest laboratory angles that could be used in the experiments was $7.5^{\circ}$. Consequently, we are not sensitive to $\mathrm{C}_{3} \mathrm{H}_{6}$ products formed with translational energies below $\sim 90 \mathrm{~kJ} / \mathrm{mol}$.

We used a bimodal $\mathrm{P}(\mathrm{E})$ distribution, similar to that reported by Zhang and coworkers, to simulate our $\mathrm{m} / \mathrm{e}=42$ photoproducts. As shown in the lower panel of figure $\mathrm{S} 4$, the $\mathrm{P}(\mathrm{E})$ is broad and extends to $\sim 390 \mathrm{~kJ} / \mathrm{mol}$, with the most probable value for the higher energy component lying at $\sim 209 \mathrm{~kJ} / \mathrm{mol}$. This $\mathrm{P}(\mathrm{E})$ adequately reproduced the measured TOF spectra.

It is interesting to note that the leading edge of the $\mathrm{P}(\mathrm{E})$ for the $\mathrm{C}-\mathrm{H}$ bond fission channel in 2propyl extends well beyond the calculated thermodynamic value of $\sim 337 \mathrm{~kJ} / \mathrm{mol}$ for vibrationally cold propene $+\mathrm{H}$ products. This indicates the presence of significant amounts of vibrational energy and is consistent with similar observations for the corresponding $\mathrm{C}-\mathrm{C}$ bond fission channel in 2propyl photodissociation.

\section{iii. C-H Bond Fission Channel in the Photodissociation of 1-Propyl Radical at $248 \mathrm{~nm}$}

In addition to the $\mathrm{C}-\mathrm{C}$ bond fission channel, we also examined the $\mathrm{C}-\mathrm{H}$ bond fission channel in the $248 \mathrm{~nm}$ photodissociation of 1-propyl radicals, leading to $\mathrm{C}_{3} \mathrm{H}_{6}$ (propene) $+\mathrm{H}$ products. As illustrated in figure S5, we monitored this channel by recording experimental TOFs at $\mathrm{m} / \mathrm{e}=42$, attributable to the propene products. The solid pink lines are the optimized TOF spectra, calculated using the $\mathrm{P}(\mathrm{E})$ shown in the lower portion of the figure. As mentioned above, due to the constraints of our current experimental set-up, the smallest laboratory angles recorded was $7.5^{\circ}$. 
We used bimodal $\mathrm{P}(\mathrm{E})$ distributions, very similar to those reported by Zhang and coworkers, to simulate our $\mathrm{m} / \mathrm{e}=42$ photoproducts. As shown in the lower panel of figure $\mathrm{S} 5$, the $\mathrm{P}(\mathrm{E})$ is broad and extends to $\sim 360 \mathrm{~kJ} / \mathrm{mol}$, with the most probable value for the higher energy component lying at $\sim 226 \mathrm{~kJ} / \mathrm{mol}$. This $\mathrm{P}(\mathrm{E})$ adequately reproduced the measured TOF spectra. We note however, that because the minimum laboratory angle was 7.5 degrees, we are not sensitive to propene products with translational energies below $\sim 90 \mathrm{~kJ} / \mathrm{mol}$.

\section{iv. Determination of the Anisotropy Parameters ( $\beta$ ) for the C-C Bond Fission Channels in the Photodissociation of 1- and 2- Propyl Radicals at $248 \mathrm{~nm}$}

We examined the dependence of the signal intensities as a function of the $248 \mathrm{~nm}$ incident laser polarization angle, for the $\mathrm{C}-\mathrm{C}$ bond fission channel products. For these experiments, a pile of plates polarizer, consisting of 24 fused silica plates mounted at Brewster's angle, produced $>98 \%$ horizontally polarized laser output. A half waveplate was then used to rotate the polarization to several different angles relative to the detector axis. In figure $\mathrm{S} 6$, the TOFs for $\mathrm{CH}_{3}(\mathrm{~m} / \mathrm{e}=15)$ products, arising from the photolysis of 2-propyl radicals, are shown at the polarization angles, $\theta_{\text {pol }}$ $=-26^{\circ}$ and $64^{\circ}$, corresponding to the polarization angles for the expected minimum and maximum signal intensities, respectively, assuming an anisotropy parameter $(\beta)=-1.00$, for the incident 248 $\mathrm{nm}$ laser excitation. Similarly, in figure $\mathrm{S} 7$, the recorded TOFs for $\mathrm{C}_{2} \mathrm{H}_{5}(\mathrm{~m} / \mathrm{e}=29)$ products, arising from the photolysis of 1-propyl radicals, are shown at $\theta_{\mathrm{pol}}=-58^{\circ}$ and $32^{\circ}$. Within the signal-to-noise ratios, no discernable polarization dependence was observed in case of either

propyl radical isomer, indicating that their respective product angular distributions for the $\mathrm{C}-\mathrm{C}$ bond fission channel are both spatially isotropic, relative to the electric vector of the incident laser beam. Hence, we report that at $248 \mathrm{~nm}$ excitation, the $\beta$ values are $0.0+/-0.2$ for both the $2-\mathrm{C}_{3} \mathrm{H}_{7}$ $\rightarrow \mathrm{CH}_{3}+\mathrm{CH}_{3} \mathrm{CH}$ and $1-\mathrm{C}_{3} \mathrm{H}_{7} \rightarrow \mathrm{C}_{2} \mathrm{H}_{5}+\mathrm{CH}_{2}$, respectively. 


\section{v. Determination of the Relative Branching Fractions of the Excited State C-C and the Total C-H Bond Fission Channels in the Photodissociation of 1-Propyl Radicals at 248 nm}

We determined the experimental relative branching fractions for the excited state $\mathrm{C}-\mathrm{C}$ and the total $\mathrm{C}-\mathrm{H}$ bond fission channels in the $248 \mathrm{~nm}$ photodissociation of 1-propyl radicals, using the following equations:

$$
\begin{gathered}
\frac{\phi_{(C-C) *}}{\phi_{C-H}}=\left(\frac{\sum_{C 2 H 5}^{e x p t}}{\sum_{C 3 H 6}^{e x p t}}\right) X\left(\frac{f_{C 3 H 6}^{i o n}}{f_{C 2 H 5}^{i o n}}\right) X\left(\frac{\sigma_{C 3 H 6}^{i o n}}{\sigma_{C 2 H 5}^{i o n}}\right) X\left(\frac{\Sigma_{C 3 H 6}^{c a l c}}{\sum_{C 2 H 5}^{c a l c}}\right) \\
\text { and, } \phi_{(C-C) *}+\phi_{C-H}=1
\end{gathered}
$$

In the above equations, $\phi_{(C-C) *}$ and $\phi_{C-H}$ are the relative branching fractions for the excited state $\mathrm{C}-\mathrm{C}$ and the total $\mathrm{C}-\mathrm{H}$ bond fission channels, respectively, in the $248 \mathrm{~nm}$ photodissociation of 1-propyl radicals. The integrated areas of the experimental TOFs for $\mathrm{C}_{2} \mathrm{H}_{5}{ }^{+}$and $\mathrm{C}_{3} \mathrm{H}_{6}{ }^{+}$, respectively, at any particular laboratory angle, are represented by $\Sigma_{C 2 H 5}^{\text {expt }}$ and $\Sigma_{C 3 H 6}^{\text {expt }}$. The factors $f_{C 2 \mathrm{H} 5}^{i o n}$ and $f_{C 3 \mathrm{H} 6}^{i o n}$ are the fractions of $\mathrm{C}_{2} \mathrm{H}_{5}$ and $\mathrm{C}_{3} \mathrm{H}_{6}$, that produce parent ion peaks upon 70 $\mathrm{eV}$ electron impact ionization. The absolute cross-sections for ionization of $\mathrm{C}_{2} \mathrm{H}_{5}$ and $\mathrm{C}_{3} \mathrm{H}_{6}$ upon $70 \mathrm{eV}$ electron impact ionization are $\sigma_{\mathrm{C} 2 \mathrm{H} 5}^{i o n}$ and $\sigma_{\mathrm{C} 3 \mathrm{H} 6}^{i o n}$. The integrated areas of the calculated best fit TOF spectra for $\mathrm{C}_{2} \mathrm{H}_{5}$ and $\mathrm{C}_{3} \mathrm{H}_{6}$ products, at that same laboratory angle, and assuming equal relative branching fractions for the two channels, are $\Sigma_{C 2 H 5}^{c a l c}$ and $\Sigma_{C 3 H 6}^{c a l c}$.

We experimentally determined the factors $f_{C 2 \mathrm{H} 5}^{i o n}$ and $f_{\mathrm{C} 3 \mathrm{H} 6}^{i o n}$ through studies of the photodissociation of $\mathrm{C}_{2} \mathrm{H}_{5} \mathrm{I}$ at $248 \mathrm{~nm}$, and from studies of beams containing $\mathrm{C}_{3} \mathrm{H}_{6}$. It was found that $\sim 23 \%$ of the nascent $\mathrm{C}_{2} \mathrm{H}_{5}$ products survives as $\mathrm{m} / \mathrm{e}=29$; the rest fragmenting to give daughter ions at $\mathrm{m} / \mathrm{e}=28,27$ and 26. Similarly, it was found that $\sim 18 \%$ of the nascent $\mathrm{C}_{3} \mathrm{H}_{6}$ products survives as $\mathrm{m} / \mathrm{e}=42$; the rest fragmenting to give daughter ions at $\mathrm{m} / \mathrm{e}=41,40,39,38,37,36,28$, 27, 26, 25, 15 and 14. The respective absolute electron impact ionization cross-sections at $70 \mathrm{eV}$ for $\mathrm{C}_{2} \mathrm{H}_{5}$ and $\mathrm{C}_{3} \mathrm{H}_{6}$ were determined to be $576.9 \mathrm{Mb}$ and $873.6 \mathrm{Mb}$, respectively. ${ }^{7}$ The value for $\mathrm{C}_{2} \mathrm{H}_{5}$ was taken as the average of the values for $\mathrm{C}_{2} \mathrm{H}_{4}$ and $\mathrm{C}_{2} \mathrm{H}_{6}$.

We calculated the integrated areas for the simulated best fits TOFs, obtained using the forward convolution program which takes into account the Jacobian factors arising from different $\mathrm{P}(\mathrm{E}) \mathrm{s}$, 
for $\mathrm{C}_{2} \mathrm{H}_{5}$ and $\mathrm{C}_{3} \mathrm{H}_{6}$ photoproducts, to determine $\Sigma_{C 2 H 5}^{c a l c}$ and $\Sigma_{C 3 H 6}^{c a l c}$. Using the appropriate values, we find that the relative branching fractions for the excited state $\mathrm{C}-\mathrm{C}$ and the total $\mathrm{C}-\mathrm{H}$ bond fission channels in 1-propyl photodissociation are $\sim 0.64$ and 0.36 , respectively. 


\section{Supplementary Figures}

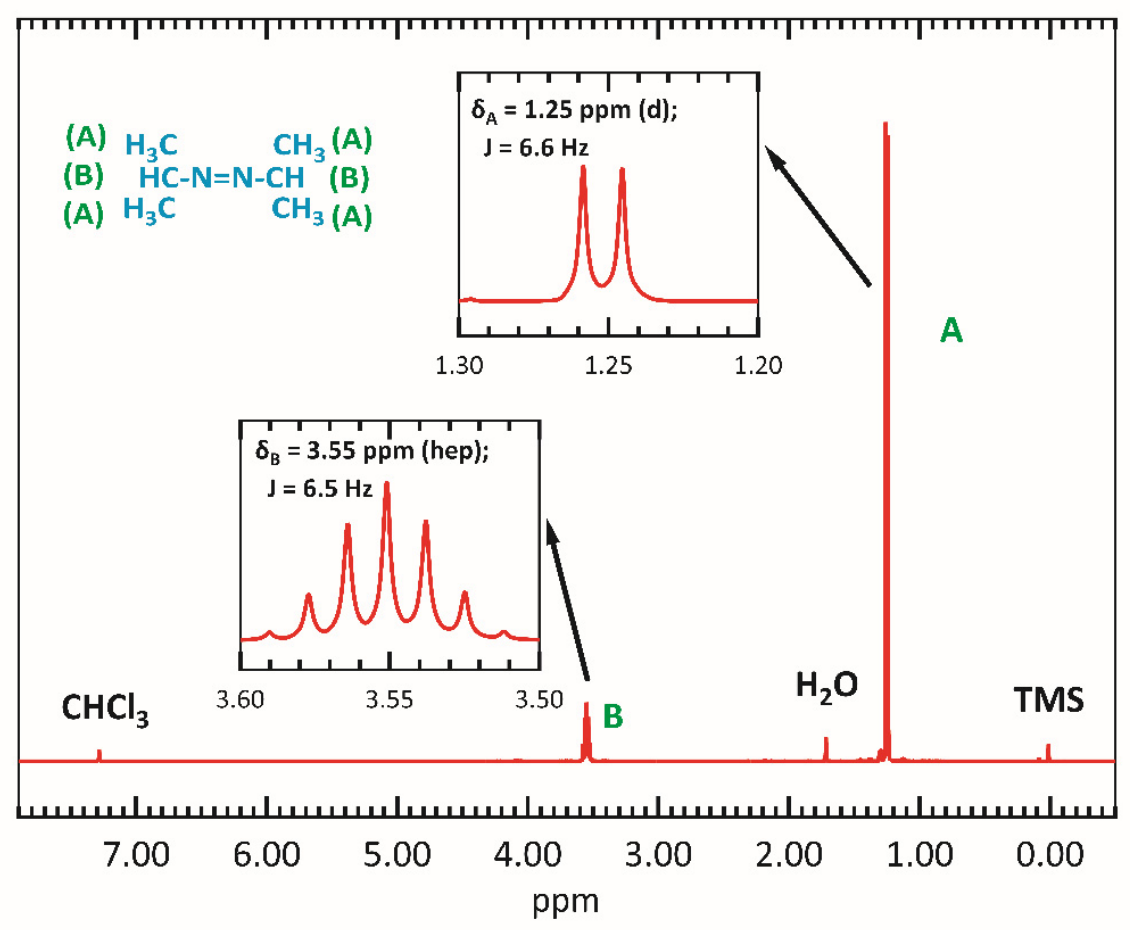

Figure S1. ${ }^{1} \mathrm{H}$ NMR spectrum $\left(500 \mathrm{MHz} ; \mathrm{CDCl}_{3}\right.$ solvent) of 2-azopropane. 


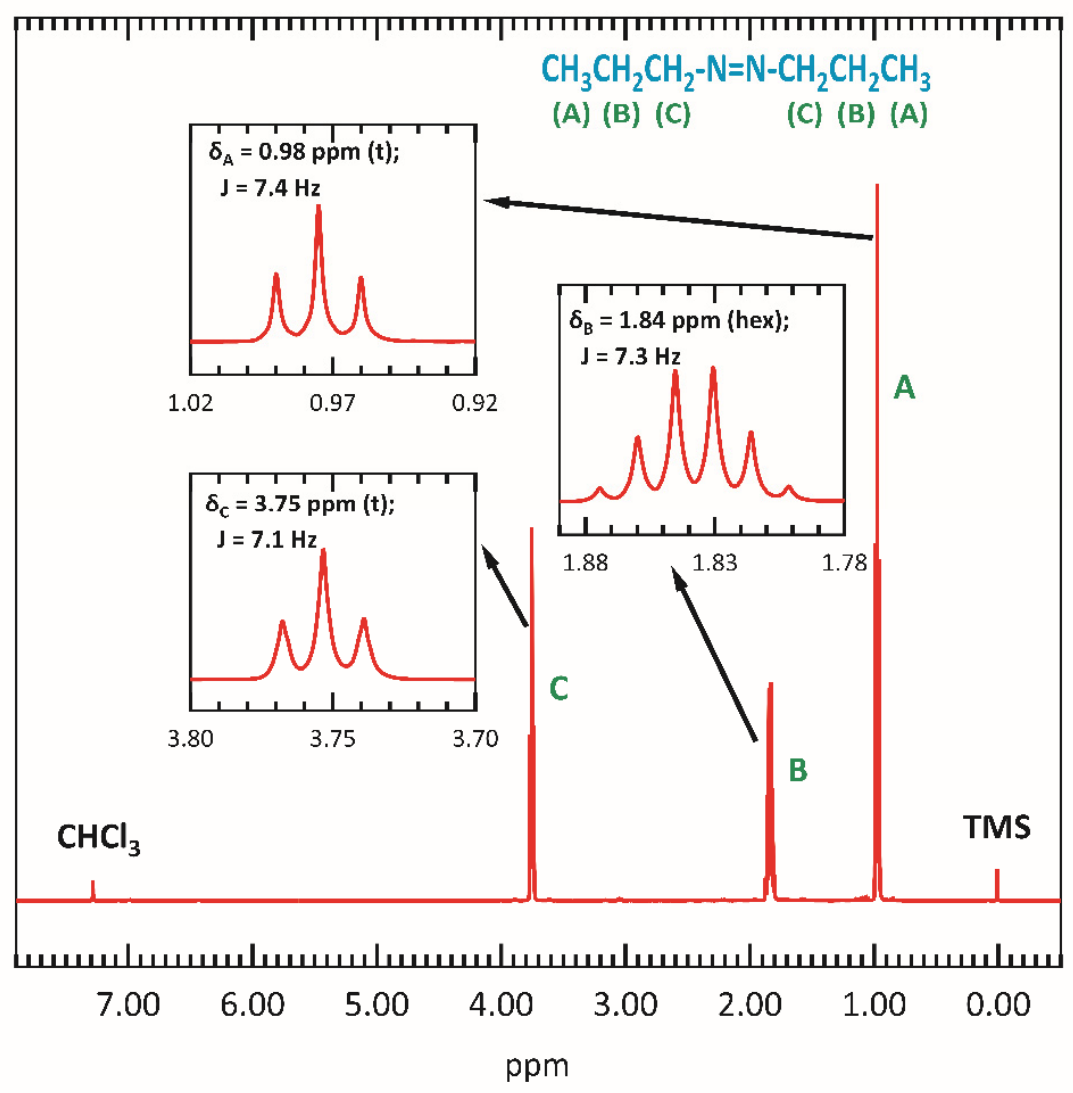

Figure S2. ${ }^{1} \mathrm{H}$ NMR spectrum $\left(500 \mathrm{MHz} ; \mathrm{CDCl}_{3}\right.$ solvent) of 1-azopropane. 

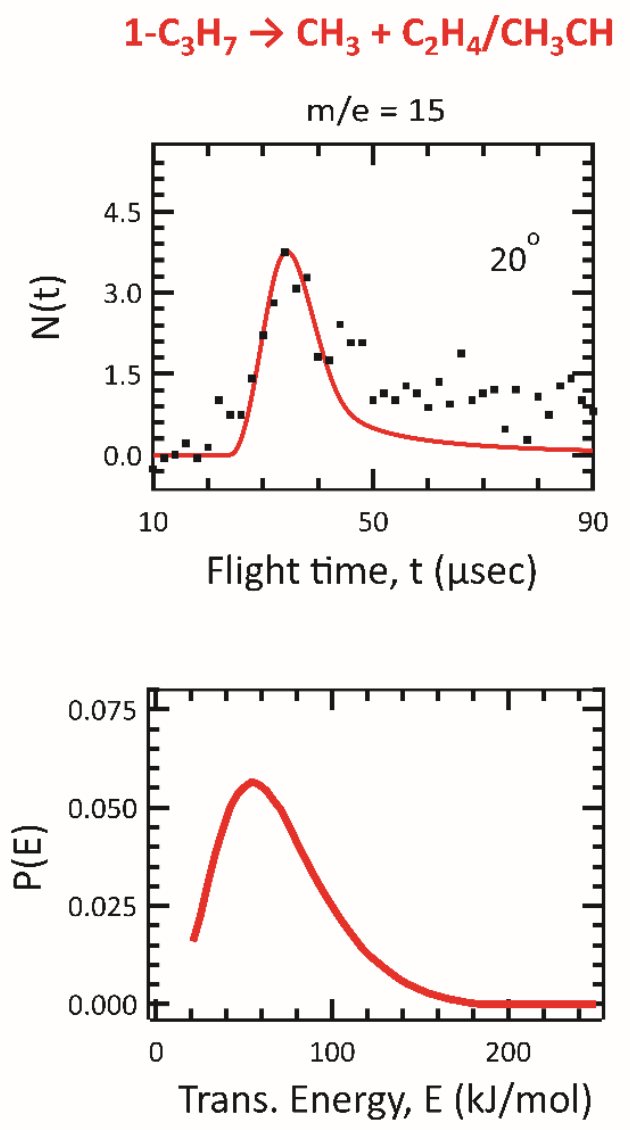

Figure S3. Upper: TOF spectra at indicated laboratory angles for $\mathrm{CH}_{3}(\mathrm{~m} / \mathrm{e}=15)$ products from $248 \mathrm{~nm}$ photodissociation of 1-propyl radicals. Solid red lines are calculated TOF spectra for $\mathrm{CH}_{3}+$ $\mathrm{C}_{2} \mathrm{H}_{4} / \mathrm{CH}_{3} \mathrm{CH}$ channel. Lower: Optimized $\mathrm{P}(\mathrm{E})$ distribution. 

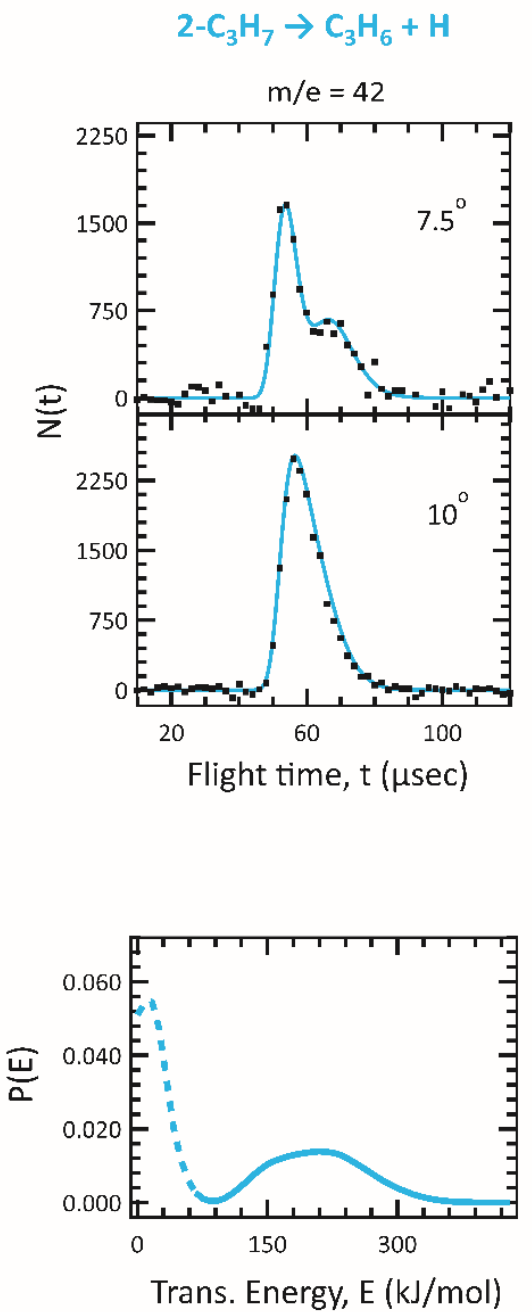

Figure S4. Upper: TOF spectra at indicated laboratory angles for $\mathrm{C}_{3} \mathrm{H}_{6}(\mathrm{~m} / \mathrm{e}=42)$ products from $248 \mathrm{~nm}$ photodissociation of 2-propyl radicals. Black dots are experimental data; solid blue lines are calculated TOF spectra for $\mathrm{C}_{3} \mathrm{H}_{6}+\mathrm{H}$ channel. Lower: Optimized $\mathrm{P}(\mathrm{E})$ distribution. 

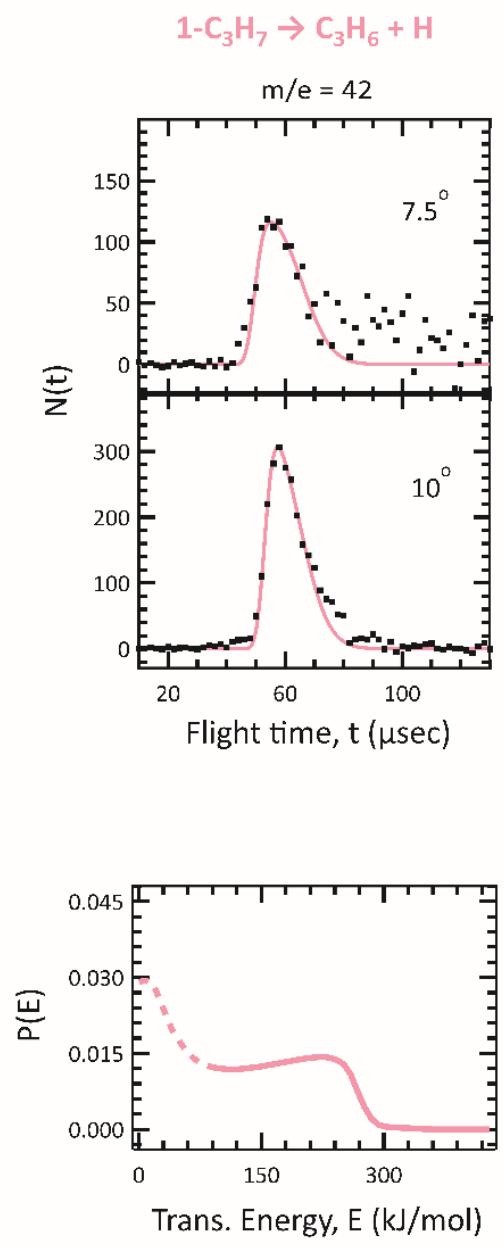

Figure S5. Upper: TOF spectra at indicated laboratory angles for $\mathrm{C}_{3} \mathrm{H}_{6}(\mathrm{~m} / \mathrm{e}=42)$ products from $248 \mathrm{~nm}$ photodissociation of 1-propyl radicals. Solid pink lines are calculated TOF spectra for $\mathrm{C}_{3} \mathrm{H}_{6}+\mathrm{H}$ channel. Lower: Optimized $\mathrm{P}(\mathrm{E})$ distribution. 


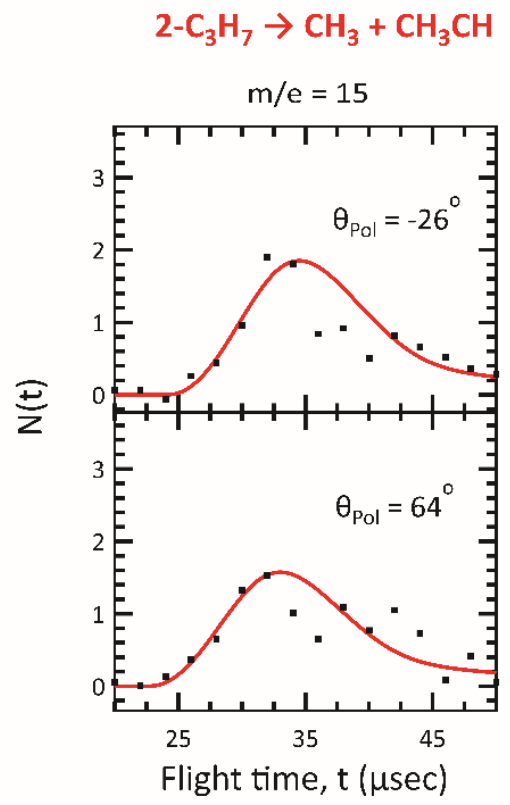

Figure S6. TOF spectra, at laboratory angle of $20^{\circ}$, for $\mathrm{CH}_{3}(\mathrm{~m} / \mathrm{e}=15)$ products from 248 $\mathrm{nm}$ photodissociation of 2-propyl radicals, at indicated polarization angles for the incident photolysis laser beam. Black dots are experimental data; solid red lines are calculated TOF spectra for $\mathrm{CH}_{3}+\mathrm{CH}_{3} \mathrm{CH}$ channel. The anisotropy parameter $(\beta)$ for this channel is $0.0+/-0.2$. The relevant $\mathrm{P}(\mathrm{E})$ is depicted in Figure 2 of the main article. 


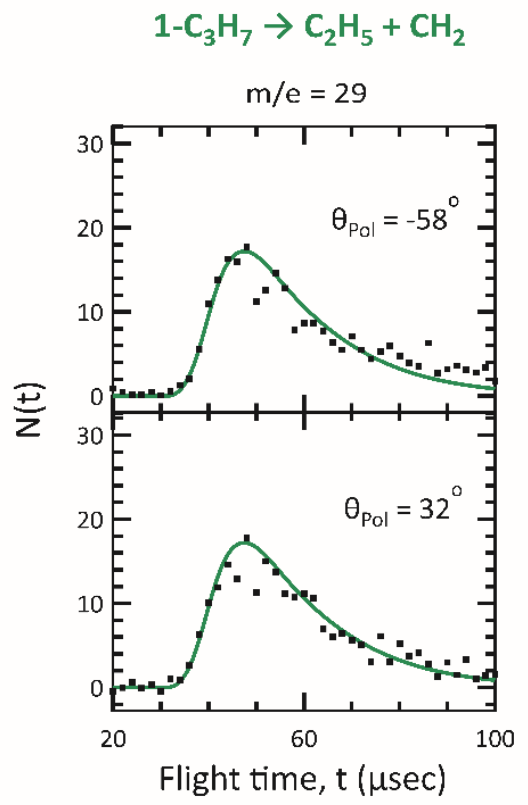

Figure S7. TOF spectra, at laboratory angle of $15^{\circ}$, for $\mathrm{C}_{2} \mathrm{H}_{5}(\mathrm{~m} / \mathrm{e}=29)$ products from 248 $\mathrm{nm}$ photodissociation of 1-propyl radicals, at indicated polarization angles for the incident photolysis laser beam. Solid green lines are calculated TOF spectra for $\mathrm{C}_{2} \mathrm{H}_{5}+\mathrm{CH}_{2}$ channel. The anisotropy parameter $(\beta)$ for this channel is $0.0+/-0.2$. The relevant $\mathrm{P}(\mathrm{E})$ is depicted in Figure 1 of the main article. 


\section{References:}

1. Yang, X.; Lin, J.; Lee, Y.T.; Blank, D.A.; Suits, A.G.; Wodtke, A.M. Universal crossed molecular beams apparatus with synchrotron photoionization mass spectrometric product detection. Rev. Sci. Instrum. 1997, 68, 3317-3325.

2. Albert, D.R.; Proctor, D.L; Davis, H.F. High-Intensity coherent vacuum ultraviolet source using unfocussed commercial dye lasers. Rev. Sci. Instrum. 2013, 84, 063104.

3. Kohn, D.W.; Clauberg, H.; Chen, P. Flash Pyrolysis nozzle for generation of radicals in a supersonic jet expansion. Rev. Sci. Instrum. 1992, 63, 4003.

4. Renaud, R.; Leitch, L.C. Synthesis of 1,2-dialkylhydrazines and the corresponding azoalkanes. Can. J. Chem. 1954, 32, 545.

5. Hu, C.-H.; Ma, B.; Schaefer, H.F. The synchronous thermal decomposition mechanism of azoisopropane. Mol. Phys. 1995, 85, 769.

6. Miller, J.A.; Klippenstein, S.J. Dissociation of propyl radicals and other reactions on a $\mathrm{C}_{3} \mathrm{H}_{7}$ potential. J. Phys. Chem. A. 2013, 117, 2718-2727.

7. Kim, Y.-K.; Irikura, K.K.; Rudd, M.E.; Ali, M.A.; Stone, P.M.; Chang, J.; Coursey, J.S.; Dragoset, R.A.; Kishore, A.R.; Olsen, K.J.; Sansonetti, A.M.; Wiersma, G.G.; Zucker, D.S.; Zucker, M.A. Electron-impact cross sections for ionization and excitation database, 2004; available at https://physics.nist.gov/PhysRefData/Ionization/molTable.html. 